\title{
Aprender a conviver, sem violência: o que dá e não dá certo?
}

Ivar César Oliveira de Vasconcelos ${ }^{\mathrm{a}}$

\section{Resumo}

Considerada ainda agente de socialização e mudança, a escola tem experimentado a violência. Neste trabalho, apresentam-se recomendações para eliminar ou amenizar o problema. Analisam-se resultados de estudos, por meio de pesquisa da literatura, focalizando-se o que dá certo em ações escolares para concretizar a adequada convivência. Algumas lógicas de ação são apresentadas: membros da escola se culpam mutuamente pelo fracasso escolar, silenciam a crítica construtiva e negligenciam a articulação entre informar formar. Conclui-se que a superação dessas lógicas pode contribuir para a solução da violência escolar. Assim, emergem possibilidades de ação por parte dos elaboradores e executores de currículos, educadores, gestores e formadores de mestres e professores. Além disso, conclui-se que, para superar a violência escolar, não dão certo os castigos corporais e as humilhações públicas, as rotulações e a intolerância; mas, dão certo, a escuta às vítimas, a aproximação entre pais e comunidade educativa, o fim da punição, o fim da culpabilização do outro.

Palavras-chave: Convivência. Violência escolar. Lógicas de ação. Pedagogia. Diálogo.

\section{Introdução}

Uma escola se constitui no encontro entre três amplas esferas de atuação: a sala de aula, enquanto microssistema; o projeto curricular, como um mesossistema; a administração escolar, enquanto um exossistema e, finalmente, a sociedade/valores/ cultura global, como um macrossistema (PESCADOR; DOMÍNGUEZ, 2001). Efetivamente, ela se situa na encruzilhada da educação de casa com a educação do mundo. É um agente de socialização e mudança. Contudo, exerce esse papel em meio à violência, podendo-se traduzir tal cenário indesejado como "violência da escola, na escola e contra a escola". Dessa maneira, no jogo de mútuas influências com o lado de fora, a escola tem deixado de ser uma instituição tão somente invadida pelo problema da violência para transformar-se numa máquina de sua reprodução.

a Universidade Católica de Brasília. Brasília, Distrito Federal, Brasil.

Recebido em: 08 nov. 2016

Aceito em: 09 mai. 2017 
Frequentemente convertida num verdadeiro laboratório de violências, a escola pode ser representada como o lugar da interação entre a "casa" e a "rua", dois espaços sociais básicos capazes de prover uma leitura sui generis da estrutura sociocultural brasileira (DAMATTA, 2004). A rua, local do trabalho, do Estado e das leis, da subcidadania (ser sujeito à lei), contrasta com a casa, local da tranquilidade do lar, das tradições de família, da supercidadania (ser dono das normas inscritas nos corações). Como a escola lida frequentemente com as diferenças sociais e culturais e, atualmente, muito em função do aumento de oportunidades de acesso à escolarização, ela recepciona subjetividades e objetividades. Constitui-se no elo pulsante entre leis que governam a rua, as instituições, o espaço público em geral, e os hábitos de casa, onde está o coração de seus membros. Caso ela não saiba lidar com essa condição de espaço interativo, forjam-se potenciais de violência escolar.

No Brasil, enquanto representações da estrutura sociocultural, a "casa" e a "rua" parecem andar distantes uma da outra. Com relação à violência, tal diferenciação só contribui para acirrar o problema. Por aqui, o sujeito violento não é o Eu, mas, sim, o Outro, pois, amiúde, as duas partes têm ocupado moradas éticas diferentes. A violência por aqui também se relaciona com a percepção de que o Eu sabe das coisas, é crítico; o Outro, alienado... Esse pano de fundo, assim explicado, transforma a escola numa bomba-relógio. Com regras de coexistência abissalmente separadas em termos antropológicos, o cenário favorece a violência escolar. Seus membros, inclusive alunos, se elegem culpados, de acordo com a avaliação superficial de cada implicado. A informação que alimenta o aprendizado desprovido de significado circula numa velocidade estonteante. Num cenário de informações abundantes, e a escola é ponto de confluência de informações, a capacidade de suportar éticas ambíguas se torna insustentável. Desse modo, abrem-se flancos para a confusão de ideias, comportamentos e decisões, originária da lida com duas leis, em especial se o ponto de referência for o problema da violência escolar. Verifica-se o potencial explosivo forjado ao longo do tempo na cabeça de crianças e adolescentes inseridos em tal ambiguidade ética.

Esse potencial explosivo, na forma como se coloca, não tem sido explorado em pesquisas, embora se avolumem estudos e publicações relacionados à violência escolar. Periódicos divulgam trabalhos com destaque para os conflitos, indisciplina e violência na escola (p. ex., MARTINS; BOTLER, 2016), apresentando causas e alternativas de ação, sem se situarem diretamente no âmbito das explicações ora colocadas.

Essas explicações, de cunho filosófico-social-antropológico, possibilitam indagar: Quais alternativas de ação nas escolas podem ser traduzidas em termos de "o que não dá certo" e "o que dá certo" para a concretização da convivência adequada e, 
assim, eliminar ou, pelo menos, amenizar a violência escolar? Espera-se contribuir para a discussão, à elaboração e ao aprimoramento de políticas públicas e com a busca de soluções práticas para o problema da violência escolar.

\section{A venenosa associação entre lógicas de ação e violência}

Possivelmente, três lógicas de ação a partir das quais os membros da escola elaboram suas experiências sociais (DUBET, 1994) potenciam a violência escolar. Inscritas nas lógicas culturais da modernidade e da pós-modernidade, portanto, mergulhadas nos valores da sociedade capitalista e capitalismo tardio, elas já foram reconhecidas em estudo anterior, envolvendo jovens estudantes e professores em cursos de licenciatura (VASCONCELOS; GOMES, 2015).

Segundo tal estudo, há a internalização de que o Outro é preferencialmente o culpado pelo fracasso escolar. E quem é este Outro? Para os professores, a universidade é o outro; para a universidade, o professor é o outro; para os estudantes, universidade e professores são os outros. Essa lógica baseia a tendência da inércia já percebida no sistema educacional. Em segundo lugar, há bloqueios à crítica construtiva de alunos e professores, base da tendência à negação parcial do sujeito - o ser humano pensa, emociona-se e age. Em terceiro e último lugar, existe a primazia da informação, tornando ausente a articulação de aspectos cognitivos e socioemocionais do ato educativo, com tendência à elaboração de algum tipo de autoritarismo - quem sabe, manda! Com tais lógicas de ação e tendências, também presentes nos cursos de formação dos professores, admite-se a instalação de uma estrutura reprodutiva que, por sua vez, se reproduz na educação básica.

O citado estudo denotou uma relação dialética entre "lógicas de ação/tendências" e o contexto cultural da "ambiguidade ética". Provavelmente, no ambiente da sala de aula, espaço prioritário das relações na escola, essa dialética impulsiona o problema da violência escolar, perpassando a formação inicial de professores e a sua atuação na educação básica - imperando o conservantismo, com o qual, quem forma tende a agir de acordo com as experiências tidas com seus professores, tenham elas sido boas ou ruins (BEEBY, 1979). Assim, nesse ambiente específico da escola, a sala de aula, o professor passa a construir e a lidar com uma pedagogia reprodutora, sem perceber, de imediato, que pode contribuir para gerar violência. Os quatro pilares da educação para o século XXI (DELORS et al., 1998) ficam ameaçados, principalmente quanto ao princípio "aprender a conviver".

Caso se aceite a possibilidade dessa configuração teórica, é razoável afirmar que a violência se instala na escola, em primeiro lugar, porque as mencionadas lógicas de ação se infiltram na dinâmica curricular. Já em dificuldade para dialogar com 
os jovens, pois os mantém distanciados de seu protagonismo, o currículo fica impregnado por experiências sociais, de educandos e educadores, construídas de acordo com a ideia de que o outro é o culpado pelo insucesso do processo educacional. Fortalece-se o currículo antidialógico.

Em segundo lugar e, até em decorrência do primeiro motivo, colegas e educadores agem em prol do arbitrário cultural (BOURDIEU; PASSERON, 1964), construindo experiências sociais reproduzidas com regularidade: os membros da escola, além de se culparem, não exercitam a crítica construtiva e priorizam a informação, em lugar de articulá-la com a formação. Esse arranjo lesivo se revigora em meio à inércia, os envolvidos no ato educativo não se reconhecem na crítica e o autoritarismo toma fôlego. Com efeito, origina-se o círculo vicioso através do qual o professor, ao deparar-se tanto com as próprias falhas como com as dos estudantes, culpa-se e os culpabiliza pelos insucessos. Ocorre mais ou menos assim: "os professores não sabem o que os alunos pensam, apenas supõem" (CUSHMAN; ROGERS, 2009, p. 194).

Nessa dinâmica, em terceiro e último lugar, a gestão da escola tende a adotar paliativos, sem agir no núcleo do problema. Fundamentada na hipocrisia organizacional (BRUNSSON, 2007), sabe que as iniciativas propostas serão infrutíferas, contudo, força o discurso do sucesso. Reiteradamente, proclama determinados valores, sem praticá-los (TEIXEIRA, 1962). Entretanto, no caso da violência, a escola não é só paciente, mas também agente, pois reproduz a estrutura de violência aparelhada ao longo do tempo e em diversos espaços.

\section{Método}

Além da literatura em geral, contou-se com publicações nacionais e internacionais divulgadas pela Coordenação de Aperfeiçoamento de Pessoal de Nível Superior (Capes), sexagenária instituição, criada para apoiar a formação docente e a pesquisa (CURY, 2005): a) artigos classificados como A1; b) outros artigos em Periódicos; c) teses de estudantes de universidades com avaliação considerada boa. No total, analisaram-se 19 trabalhos publicados no período 2012-2016, com acesso livre na Internet.

Do universo de 47 periódicos A1, selecionaram-se 27, para, enfim, chegar à quantidade de oito - tais periódicos continham artigos em que os títulos apresentavam o termo "violência" em português, inglês ou espanhol. Então, analisaram-se 13 artigos com pesquisas bibliográficas, estudos de campo, estudos de caso, método econométrico e pesquisa-intervenção, realizadas no Brasil, Portugal, Espanha e México, além de uma resenha. Ao termo "violência" acrescentou-se "escolar" para escolher artigos disponibilizados 
como Periódicos da Capes, um espaço virtual que oferece acesso a mais de 37 mil publicações. Desse nível mais amplo, extraiu-se o universo de nove revistas, finalizando com a análise de três artigos que apresentaram pesquisa bibliográfica, estudo de campo e estudo de caso, com desenvolvimento no Brasil, Portugal e Chile (Quadro 1).

Das 195 universidades brasileiras, 87 disponibilizam seus trabalhos à Biblioteca Digital Brasileira de Teses (BDBT). Com o auxílio do e-Mec, escolheram-se as universidades de onde se extrairiam os estudos para análise. Optou-se por tomar como universo as 13 universidades melhor pontuadas. Destas, quatro estão na BDBT, cada uma delas com uma tese, cujo título apresenta o termo "violência escolar". Contudo, três teses compuseram a terceira fonte de coleta de dados (Quadro 2), cujas pesquisas se caracterizam como: estudos de campo e pesquisa experimental (Brasil).

Para proceder às análises, os dados coletados foram organizados, verticalmente, conforme o tipo de violência/vítimas, as recomendações e os benefícios decorrentes da instauração destas. Em seguida, horizontalmente, organizaram-se de acordo com o âmbito de tais benefícios: a dinâmica curricular, as interações sociais dos envolvidos no ato educativo e a gestão escolar, apontando diretamente para o rompimento da reprodução da violência escolar.

Quadro 1. Periódicos $A 1$ e outros Periódicos (divulgados pela) Capes.

\begin{tabular}{|c|c|c|c|c|}
\hline \multirow{2}{*}{ Periódicos } & \multirow{2}{*}{$\begin{array}{l}\text { Participaram } \\
\text { da pesquisa? }\end{array}$} & \multirow{2}{*}{ Critérios de seleção do periódico } & \multicolumn{2}{|c|}{ Quantidade } \\
\hline & & & Periódico & Artigo \\
\hline \multirow[t]{4}{*}{ A1 } & Sim & $\begin{array}{l}\text { Contendo artigos com "violência" no } \\
\text { título, sendo da área da educação. }\end{array}$ & 7 & 13 \\
\hline & & $\begin{array}{l}\text { Contendo artigos com "violência" no } \\
\text { título, mas sem ser da área da educação. }\end{array}$ & 1 & - \\
\hline & & Sem artigos com "violência" no título. & 19 & - \\
\hline & Não & $\begin{array}{l}\text { Periódicos com artigos cujo acesso é } \\
\text { pago, com entrega em impresso. }\end{array}$ & 20 & - \\
\hline Subtotais & & & 47 & 13 \\
\hline \multirow[t]{2}{*}{ Capes } & Sim & $\begin{array}{l}\text { Contendo artigos com "violência escolar" } \\
\text { no título, sendo da área da educação. }\end{array}$ & 3 & 3 \\
\hline & Não & $\begin{array}{l}\text { Contendo artigos com "violência } \\
\text { escolar" no título, mas sem } \\
\text { ser da área da educação. }\end{array}$ & 6 & - \\
\hline Subtotais & & & 9 & 3 \\
\hline Totais & & & 56 & 16 \\
\hline
\end{tabular}

Fonte: elaboração do autor (2016), com base na Plataforma Sucupira (CAPES, 2016a) e Portal de Periódicos da Capes/MEC (CAPES, 2016b). 
Quadro 2. Universidades na Biblioteca Digital Brasileira de Teses.

\begin{tabular}{llcc}
\hline \multirow{2}{*}{$\begin{array}{l}\text { Participaram da } \\
\text { pesquisa? }\end{array}$} & $\begin{array}{l}\text { Critérios de seleção } \\
\text { da universidade }\end{array}$ & Universidade & Quantidade \\
\hline Sim & $\begin{array}{l}\text { Contendo teses com } \\
\text { "violência escolar" no } \\
\text { título. }\end{array}$ & 3 & 3 \\
Não & $\begin{array}{l}\text { Contendo teses } \\
\text { com "violência } \\
\text { escolar" no título, } \\
\text { mas a violência foi } \\
\text { originada na família } \\
\text { e não na escola. }\end{array}$ & 1 & \\
& $\begin{array}{l}\text { Universidades sem } \\
\text { teses com "violência } \\
\text { escolar" no título. }\end{array}$ & 9 & \\
Totais & & & \\
\hline
\end{tabular}

Fonte: elaboração do autor (2016), com base na BDBT (IBICT, 2016) e e-Mec (BRASIL, 2016).

\section{O que não dá certo}

Os diversos efeitos das violências sofridas por alunos, frequentemente, são tratados com mais violência na escola, alimentando a reprodução deste problema. Por exemplo, aqueles com mães vítimas da violência de gênero (ROSSER LIMIÑANA; SURIÁ MARTÍNEZ; VILLEGAS CASTRILLO, 2015) não têm encontrado solução para o baixo rendimento apresentado na escola, para o absenteísmo escolar, para a desmotivação, bem como para a desatenção e a falta de concentração. Não pode dar certo tratar essas consequências com mais violência, como as famosas humilhações públicas ou até castigo corporais que, no fundo, transmitem a mensagem de que o aluno é o culpado pelo seu sofrimento.

Mais conflito e intolerância também não resolvem, frequentemente, traduzidos em termos de transferência de responsabilidade (MARTINS; MACHADO, 2016). Não se pode imaginar, como eficaz alternativa de ação, a chamada tolerância zero, a tática do "bateu, levou" (DEBARBIEUX, 2006; PAULO; ALMEIDA, 2015). Isso perpetua o desejo de continuar "batendo".

Já os problemas de indisciplina de alunos não serão resolvidos por meio da rotulação deles como indisciplinados ou mal educados. Muito menos, vinculando tal comportamento à questão familiar. Segundo Caeiro e Delgado (2005), além de não resolver, isso reforçará essa mesma característica neles. 
Para esse problema, uma alternativa que também não dá certo é a instalação de câmeras em pontos estratégicos da escola, uma discussão ainda sem consenso, um paliativo já condenado por especialistas. Há nessa proposta o perigo de negligenciar-se o diálogo entre pais e filhos, o de transformar-se tal estratégia uma arma contra os professores (aqui se instala o medo na escola, abre-se para a perseguição de docentes) ou ainda um prejuízo à socialização dos alunos. Principalmente neste caso, veja-se essa notícia num jornal de Brasília: Sabendo que era vista por parentes enquanto estava na escola, "uma menina de 4 anos, por exemplo, mandava beijo e dava tchau para a avó em Belo Horizonte diariamente" (KLINGL, 2009, p. 35). Acresce lembrar outros aspectos negativos nessa proposta que efetivamente transforma violência em mais violência. Por exemplo, se câmaras dentro da sala de aula leva à exposição de crianças, não seria isso mesmo uma violência contra elas? Contra o seu espaço e a sua individualidade? Assim, as tecnologias podem inibir condutas indesejadas, porém, não alteram efetivamente valores, atitudes e comportamentos. Pelo contrário, podem trazer problemas psíquicos que alimentarão a violência.

Essas alternativas, pouco eficazes, atingem prioritariamente crianças e adolescentes. Entretanto, não apenas contra esses, mas também contra estudantes universitários, a violência, com o intuito de superar a violência, se faz presente no desconto de pontos no aproveitamento. Essa é uma prática que não dá certo. Se o aluno é indisciplinado não adianta rotulá-lo como um indivíduo mimado, preguiçoso, imaturo e coisas do gênero e diminuir a nota de sua prova. Nada resolve tê-lo como falante, dependente, com deficiência de leitura e escrita, com valores frágeis, sem vontade de estudar, pouco esforçado (ROGGERO, 2007). Isto só contribui para o seu fracasso escolar, para desestimulá-lo e odiar a universidade. Por exemplo, este autor já escutou o seguinte depoimento de um discente do curso de Pedagogia, do quinto semestre: "durante o curso, a universidade vai-te empurrando igual a um lixo; o sexto ano é a lixeira".

Com efeito, em qualquer nível de ensino, da educação básica à superior, as práticas de muitos docentes ainda se têm baseado na punição e na eliminação, o que, em vez de contribuir para extinguir o problema da violência, reforça-o. Isto porque alimenta o descontentamento dos alunos com a escola, afastando-os desta ou levando-os a se conformar com atitudes reativas violentas. Nesse sentido, o hábito de culpá-los por manifestações de violência no ambiente escolar desfavorece a extinção da violência (RUOTTI, 2010). Não ouvi-los, e sim abarrotá-los de conceitos sem articular com a efetiva formação, pode gerar uma situação de autoritarismo, pois "manda" quem tem mais informação (VASCONCELOS; GOMES, 2015). 


\section{O que dá certo}

O que dá certo é superar as mencionadas lógicas de ação, situadas na base da violência escolar. Neste sentido, o que sugerem os estudos analisados com relação ao currículo, às interações sociais e à gestão escolar, de modo a barrar a violência escolar e sua reprodução?

\subsection{Dinâmica curricular}

Do total de trabalhos considerados, quatro recomendam iniciativas vinculadas à questão curricular ${ }^{1}$. $\mathrm{O}$ primeiro deles se debruçou sobre as violências de gênero, tendo constatado que os filhos de mulheres vítimas dessas violências têm baixo rendimento acadêmico, bem como apresentam absenteísmo escolar, desmotivação, desatenção e falta de concentração. Sugere-se o aprofundamento do tema para saber de que maneira a exposição ao problema pode afetar a vida escolar. Segundo os autores, devem-se preparar os profissionais que lidam com as vítimas, em especial, sensibilizar e formar professores. Isto contribuirá para o tratamento e a prevenção quanto aos efeitos da violência sobre as crianças (ROSSER LIMIÑANA; SURIÁ MARTÍNEZ; VILLEGAS CASTRILLO, 2015).

O segundo trabalho focalizou situações conflituosas e intolerantes na escola. Alunos e suas famílias, diretores, professores e funcionários sofrem com os conflitos originados em contextos adversos. $\mathrm{O}$ autor verificou a presença de transferência de responsabilidade pela solução da violência. Recomenda o aprofundamento de estudos sobre os Programas de Governo, lançando mão de documentos e fontes oficiais para examinar os fundamentos políticos e pedagógicos do conjunto normativo-legal e das diretrizes das reformas educacionais, contribuindo para construir um campo crítico de teorias e debates. De acordo com o autor, isso indicará caminhos para os diretores e os demais membros da escola, favoráveis ao enfrentamento de situações de conflito e violência (MARTINS; MACHADO, 2016).

O terceiro e quarto trabalhos, a partir da ideia de análises contextualizadas do problema da violência escolar, sugerem a elaboração de estratégias para aproximar pais e comunidade educativa, de modo a transformá-los em parceiros na tarefa de construir a escola menos violenta. Esses trabalhos, sendo um no Brasil (estudo de campo) e outro em Lisboa (pesquisa bibliográfica), advertem para a urgente necessidade de maior compreensão das lógicas específicas de cada evento de violência, tendo-as como um arranjo relacional. Com isto, podem ficar mais visíveis

Um quinto artigo se ateve às violências intra e extrafamiliares contra adolescentes, com base na questão de gênero. Contudo, não prioriza recomendações para eliminar o problema, e sim informações que o evidenciam. 
os incidentes violentos no âmbito da escolarização, envolvendo políticas públicas e a interação face a face na sala de aula (LOPES et al., 2012; SEBASTIÃO, 2013).

Essas recomendações se referem ao tema da convivência na escola, com redução da violência, implicando diretamente na dinâmica curricular. O currículo direcionado pela razão e informações, moldado pelos padrões da modernidade, se ressente de desenvoltura capaz de articular cognição e afeto, o que o tornaria significativo à realidade do alunado (GALVÃO et al., 2010). Seguindo-se recomendações como as que ora se apresentam, alunos e professores podem sentir-se responsáveis pelo processo educativo e clima de paz no ambiente escolar. Desaparece a mútua culpabilização pelos insucessos e pela má convivência na escola. Neste sentido, o programa antiviolência realizado junto a 307 alunos do segundo ciclo de uma escola em Lisboa mostrou ser imprescindível que, para reduzir os níveis de violência escolar, cabe realizar ações de sensibilização/formação de docentes e pais, bem como de capacitação de competências sociais dos discentes (MENDES, 2010).

\subsection{Interação social}

Muito já se disse que os recreios e os intervalos oferecem oportunidades de violência, inclusive bullying. Nesses espaços, se não há adultos a observar, com capacidade de detectar a violência, provavelmente ela reincidirá. Igualmente, os banheiros têm sido lugares de uso de drogas, de assédio sexual e de outras coisas. Nesses locais, alunos interagem entre si e podem interagir com professores. Como melhorar a convivência? Como reduzir a violência?

Nove trabalhos sugerem iniciativas, voltadas para a interação social, favoráveis ao rompimento do silêncio e do autoritarismo. Assim, supera-se a violência escolar e a sua reprodução ${ }^{2}$. Contra o bullying na escola e seus efeitos sobre a saúde físico-mental e sobre a socialização de crianças e adolescentes, estratégias podem ser sistematizadas com o objetivo de harmonizar atitudes e estilos de comunicação, sendo capazes de envolver trabalhos colaborativos entre os membros da comunidade educativa (SANTOS; RAMOS, 2016). Certamente, trabalhos que contam com a presença de adultos nos locais mais sujeitos às ações de violência - na ausência destes, os alunos se agridem, dão-se pontapés, naturalizando comportamentos desse tipo. Esses adultos precisam estar conscientes do valor da pedagogia de diálogo aberto e da mediação face à violência. Só assim, as vítimas serão protegidas e encorajadas a denunciar o(s) agressor(es).

Um décimo artigo analisado apresenta pesquisa sobre os tipos de violência, consoante percepções de professores e policiais, porém, sem explicitar ou sugerir práticas para eliminar o problema. 
Entretanto, como o problema é de mão dupla, há violência sobre os docentes. Estes são agredidos por alunos e desrespeitados pela própria micropolítica da instituição - parte deles se obriga a exercer o papel de animador com base nos imperativos do consumo e da excelência. Amordaçados, professores têm medo de falar, vendo-se sob o olhar de "possíveis olheiros no grupo". As pesquisas analisadas sugerem que o corpo docente e demais membros da escola aprofundem estudos sobre a violência conjuntural para compreender como se tornam meros operários do conhecimento, controlados, disciplinados e impotentes para a crítica e para a transformação social. Desse modo, emergirão novas interlocuções, permitindo o deslocamento do lugar de "queixa" e de "impotência" para o âmbito da reflexão em busca de alternativas (ARREGUY; COUTINHO, 2015).

Não há como negar que no meio escolar existe um acúmulo de informações inúteis, sem significado, principalmente para os alunos, o que termina por recrudescer a violência. Promover a melhor convivência passa pelo reconhecimento de que a função da escola e de seus educadores ultrapassa a dimensão do ensino de conceitos. A sugestão é incluir e reforçar assuntos relacionados com a moral, a ética e a cidadania (GOMES; NASCIMENTO; KOEHLER, 2012; BISPO; LIMA, 2014). É preciso romper a centralização do poder e do controle nos processos educacionais, cabendo à escola superar o modelo autoritário prevalecente há séculos e cabendo aos educadores conduzir os estudantes a uma convivência pacífica, pautada no diálogo, no respeito e na consciência. A educação precisa ser compreendida como um percurso de formação humana, para além da transmissão de conteúdos formais, portanto, articulando informação e formação.

Concebe-se essa articulação como o ato educativo capaz de aproximar conhecimentos teórico-práticos e desenvolvimento humano, caracterizando-se por uma abrangência maior com relação aos conhecimentos. Constitui-se na combinação "saber-consciência", realizada por meio de princípios organizadores dos saberes, contribuindo para a emergência de sentidos e, assim, preparando alunos e professores para constatar problemas, como o da violência escolar, além de saber lidar com eles.

A pesquisa de Prieto Quezada (2012), realizada com foco no sofrimento de alunos maltratados na família e na escola, e a de Crochik (2016), sobre o bullying no contexto da hierarquia entre estudantes do ensino fundamental, argumentam ser primordial recuperar a memória de crianças e adolescentes vítimas, a fim de ressarcir danos e prevenir outros casos. Para os autores, é preciso estudar essa hierarquia, considerando a popularidade dos estudantes, o seu desempenho na educação física e nas outras disciplinas. Argumentam que, sem essas iniciativas, os efeitos da violência, destrutivos da convivência escolar, não serão eliminados. 
Ainda no âmbito da interação social, três teses analisadas sugerem a busca de momentos de reflexão sobre o problema, mas fazendo-o já com a prática de encontros entre educadores, alunos e comunidade em geral. Uma delas propõe a ampliação do Programa Violência Nota Zero, viabilizado por meio de encontros com atividades expositivas, reflexivas e construção coletiva com educadores. Atividades extraencontro promovem a melhoria da fixação dos conteúdos discutidos, incluindo os alunos (STELKO-PEREIRA, 2012).

Outra tese, com foco no bullying, alerta para a necessidade de as escolas abrirem, cada vez mais, espaços para escutar seus alunos, realizando estratégias cooperativas de respeito interpessoal no cotidiano escolar. É crucial que adultos e crianças entendam a relevância do respeito à diversidade e da desconstrução de preconceitos, incluindo nesse esforço as famílias dos alunos (MANZINI, 2013). Ações desse tipo contribuirão para alcançar as causas e obter soluções para o problema da violência escolar (GONÇALVES, 2013), pois, no limite, baseiam-se na valorização da escuta.

De fato, a escuta é a abertura à maior interação, pois possibilita o exercício da alteridade pelos professores (PAULO; ALMEIDA, 2015). Em termos psicológicos, a escuta se elabora como fundo perene das interações sociais, sem a qual a violência escolar não será eliminada. Especialistas informam que, caso permaneçam as interações sociais e afetivas entre alunos e professores como aspectos marginais do processo educativo, dificilmente a escola lidará, com possibilidades de êxito, com a violência. Portanto, recomendam que professores e alunos partam do pressuposto de que a violência resulta de condições sociais desfavoráveis, mas, também, da manifestação de subjetividades. Na violência andam juntas a falta da palavra e a ruptura de laços sociais.

Portanto, essas sugestões apontam para a melhoria da convivência. No âmbito da formação de professores, essa melhoria poderá ser percebida em termos de autorresponsabilidade, por parte de estudantes e professores, pela interação social entre eles; de reconhecimento de sua capacidade crítica e de preocupação constante em articular informação e formação - potenciais de solução para o arbitrário cultural e, assim, eliminar a reprodução da violência escolar (VASCONCELOS; GOMES, 2016).

\subsection{Gestão escolar}

Os três trabalhos com recomendações voltadas à gestão escolar convergem ao valorizar a ação preventiva contra a violência. O primeiro deles analisa o Programa Comunidade Escola, tomando algumas unidades escolares de Curitiba que o 
implantaram. Busca soluções para a depredação, a pichação, a venda/consumo de drogas, a violência física e verbal contra professores e a violência física e verbal entre os alunos. Com a sua implantação, reduziram-se algumas violências, como furtos aos professores e de equipamentos pedagógicos, além dos atentados contra a vida dos alunos (FRANÇA; DUENHAS; GONÇALVES, 2013).

O segundo trabalho (CHRISPINO; GONÇALVES, 2013), de natureza bibliográfica, recomenda o aprofundamento de estudos e alternativas metodológicas para saber o "porquê" das violências, inclusive contra o patrimônio público, e modelar ações que previnam a violência. Sugere o uso de instrumentos de gestão preventiva capazes de atender às funções de "conhecimento, proteção e intervenção". Indo ao âmbito dos elaboradores de políticas públicas, o estudo sugere o protagonismo de ações proativas, buscando, no universo escolar, conhecer a realidade, quantificar, categorizar, modelar, propor soluções, avaliar resultados e replanejar rotinas. Para viabilizar essas ações, haveria de se criar um amplo sistema de pesquisa a fim de estruturar-se a gestão da violência escolar. Os autores esperam que as recomendações apresentadas possibilitem a elaboração e a execução de políticas públicas educacionais.

O terceiro e último trabalho se preocupou com a violência do mundo adulto sobre o da infância, o biopoder. Após pesquisar um colégio da educação básica chileno, os autores sugerem que os membros da escola tenham momentos de problematização da violência. Eles concluem que só assim haveria a sua maior compreensão, aliando tal entendimento ao aprendizado sobre o mundo infantil e eliminando as violências (CARRASCO-AGUILAR et al., 2016).

Essas recomendações podem contribuir para romper com a reprodução da violência. Em pesquisa sobre a probabilidade de sua produção em ambientes escolares, Silva (2013) demonstrou que futuros docentes, graduandos do curso de licenciatura em Pedagogia sofrem a violência simbólica e a reproduzem na docência. Gera-se o cenário em que alunos agridem professores e vice-versa. $\mathrm{O}$ agente exposto à violência poderá reproduzi-la quando estiver, sobretudo, na posição de quem o agrediu. Para o autor, torna-se necessário criar mecanismos teóricos e práticos eficazes para romper esse ciclo, vetando a produção da cultura de violência nos cursos de formação inicial e continuada de professores.

Desse modo, constata-se a imprescindibilidade da efetiva gestão para a convivência pacífica na escola. A instituição escolar deve primar pela promoção de relações mais respeitosas (RUOTTI, 2010). Nesse sentido, as conclusões de Galvão et al. (2010), em pesquisa com base em teses e dissertações sobre as violências escolares, retiram 
a gestão escolar da abordagem punitiva para ceder-lhe o lugar da participação, do diálogo e das normas claras, explicadas e negociadas. Essa gestão, democrática, torna-se capaz de ensinar a conviver. Com ela, não há anomia ou o império da lei do mais forte. Está centrada no aprendizado da convivência, agindo frontalmente no eixo do problema. Afasta-se da hipocrisia organizacional (BRUNSSON, 2007). Desse modo, contribui para bloquear passagens à reprodução da violência escolar.

\section{Conclusões}

O contexto social em que predomina o hábito de culpar o outro pelo fracasso escolar, o de silenciar as críticas de alunos e professores e o de priorizar a informação, sem articulá-la com a formação, reforça tendências à inércia, à negação dos sujeitos e ao autoritarismo. Assim, a venenosa associação do fracasso, da negação do sujeito, do jogo de empurra e da inércia escolar tem levado a falsas soluções, a exemplo dos castigos corporais, humilhações públicas, câmeras ligadas ou não à internet, detectores de metais, outras tecnologias de segurança, desconto de pontos no aproveitamento (uma coisa não tem a ver com outra, assim aumentando a probabilidade de fracasso), além da tolerância zero (bateu, levou) (DEBARBIEUX, 2006; PAULO; ALMEIDA, 2015).

Conquanto em parte do mundo, inclusive no Brasil, a avaliação de projetos e atividades para prevenção e superação das violências ainda seja escassa, estas estratégias seguem na contramão da emergência da subjetividade, do protagonismo dos alunos, dos métodos ativos. As tecnologias vendem, mas concretizam a distopia de Orwell (2003). Inibem, coagem, sem alterar valores, atitudes, mal-estares psíquicos ou discriminações indutores da violência. Podem evitar a capa de comportamentos, porém não adentram o centro gerador. As sanções, por sua vez, desgastam-se em função da repetitividade burocrática, perdendo grande parte da sua legitimidade.

Mas, nem tudo está perdido, como evidencia este estudo. Entre "ações que não dão certo" e "ações que dão certo", segue a escola, enquanto encruzilhada da educação de casa com a educação da rua (Quadro 3).

É preciso deter a violência, a qual transforma as pessoas em perdedoras: quem ameaça, e bate e fere, no fundo perde a dignidade porque denigre a si e ao outro por meio da negligência humana; por sua vez, quem recebe a violência, e apanha e se fere, denigre a si e ao outro porque se faz aporte da mesma negligência. Portanto, impõe-se necessário zelar pela convivência, levando professores, gestores, pais e alunos a serem verdadeiros ourives do pilar aprender a conviver (DELORS et al., 1998). 
Quadro 3. Alternativas de ação que "não dão certo" e que "dão certo".

\begin{tabular}{|c|c|}
\hline Não dão certo & Dão certo \\
\hline \multirow[t]{2}{*}{ Castigos corporais } & $\begin{array}{l}\text { Adotar na comunidade educativa o apreço pela } \\
\text { afetividade, a atenção e a empatia (interação social). }\end{array}$ \\
\hline & $\begin{array}{l}\text { Recuperar a memória de crianças e adolescentes } \\
\text { maltratadas, a fim de ressarcir danos e prevenir outros } \\
\text { casos, bem como aprofundar estudos sobre hierarquias } \\
\text { entre alunos (interação social). }\end{array}$ \\
\hline Humilhações públicas & $\begin{array}{l}\text { Adotar na escola condutas moderadas, com o controle } \\
\text { das próprias emoções (interação social). }\end{array}$ \\
\hline \multirow[t]{2}{*}{$\begin{array}{l}\text { Câmeras, detectores de } \\
\text { metais e outras tecnologias de } \\
\text { segurança }\end{array}$} & $\begin{array}{l}\text { Aproximar os pais de alunos da comunidade educativa. } \\
\text { Se possível, desenvolver estratégias formativas em que } \\
\text { todos participam juntos (dinâmica curricular). }\end{array}$ \\
\hline & $\begin{array}{l}\text { Ultrapassar a dimensão do ensino de conteúdos formais, } \\
\text { focalizando também aspectos morais, éticos, cidadãos, de } \\
\text { respeito e de consciência (interação social). }\end{array}$ \\
\hline $\begin{array}{l}\text { Desconto de pontos no } \\
\text { aproveitamento }\end{array}$ & $\begin{array}{l}\text { Eliminar imediatamente quaisquer estratégias de punição } \\
\text { (dinâmica curricular). }\end{array}$ \\
\hline \multirow[t]{3}{*}{ Tolerância zero } & $\begin{array}{l}\text { Escutar os alunos, considerando a violência como } \\
\text { resultado de condições sociais desfavoráveis (a ruptura } \\
\text { de laços sociais) e como manifestação de subjetividades } \\
\text { (a ausência da palavra) (interação social). }\end{array}$ \\
\hline & $\begin{array}{l}\text { Aprimorar ou desenvolver entre os membros da } \\
\text { comunidade escolar o hábito de dialogar. Foco: } \\
\text { harmonização de atitudes e estilos de comunicação em } \\
\text { trabalhos colaborativos (interação social). }\end{array}$ \\
\hline & $\begin{array}{l}\text { Promover entre os professores uma abertura à alteridade } \\
\text { (interação social). }\end{array}$ \\
\hline $\begin{array}{l}\text { Rotular o aluno como } \\
\text { indisciplinado e mal educado, } \\
\text { promovendo a vinculação entre } \\
\text { esse perfil e a família }\end{array}$ & $\begin{array}{l}\text { Parar de culpar os alunos por manifestações de violência } \\
\text { na escola (dinâmica curricular). }\end{array}$ \\
\hline
\end{tabular}

Fonte: elaboração do autor (2016).

No âmbito da gestão escolar, é válido desenvolver mecanismos de controle da reprodução da violência desde o ingresso até a conclusão dos cursos de formação de professores (SILVA, 2013). Nesse sentido, as recomendações identificadas nos artigos e teses analisadas durante este trabalho evidenciam a necessidade de aprofundamento de estudos pelos membros da escola: a) com relação à dinâmica curricular, estudar a violência de gênero, para saber como a exposição a ela pode afetar as pessoas, bem como estudar os Programas de Governo com foco na violência escolar, contribuindo para construir um campo crítico de teorias e debates; b) quanto à interação social, estudar a violência conjuntural, considerando aspectos da violência subjetiva e entender a educação como uma trajetória de 
formação humana, para além da transmissão de conteúdos formais, bem como realizar estudos sobre a violência escolar por intermédio de encontros entre educadores, alunos e comunidade em geral.

Confirma-se, com este trabalho, que as iniciativas para superar a violência escolar passam pela pedagogia crítico-reflexiva. Os professores necessitam capacitar-se continuamente para o estabelecimento da educação para a paz, considerando quaisquer tipos de violência escolar (VENTURA; PEDROSA VICO; VENTURA, 2016). Torna-se urgente cuidar do clima escolar e contribuir para organizar consensos baseados no respeito às diferenças. É preciso construir diálogos capazes de sedimentar a cultura com um novo rosto - efetivamente, a nova Paideia (JAEGER, 2001; ROUSSEAU, 2017). Nesse sentido, ratificam-se as conclusões de Possato et al. (2016), em pesquisa sobre o problema dos conflitos escolares, de que a escola precisa de uma "mediação intercultural, que para além da mediação interpessoal contemple como base a compreensão, o diálogo e o desenvolvimento comunitário entre culturas" (p. 364).

Freire (2015) diria que tudo isso é possível. Para além dos limites, há o inédito viável. Há a esperança. Não como espera, como item a ser meramente alcançado. Mas, como conquista, como possibilidade. Por isso mesmo, deve-se recusar com firmeza a inércia, e até o encorajamento à própria violência escolar, com frequência, presentes em programas para superá-la, pois estes, seguidamente, tendem a fixar-se em objetivos imediatos, descurando do necessário foco em ações estratégicas pautadas no dia a dia da escola (DEBARBIEUX, 2006).

Já se afirmou que escolas que fazem a diferença encontram soluções, as quais, de longe, seriam mirabolantes (GOMES; LIRA, 2010). E, para resolver os problemas da comunidade educativa, em especial, quando esta se ressente de concretude do aprendizado para a convivência, é válido considerar as evidências científicas e a aplicação de medidas simples. 


\section{How to live together: what works and what doesn't?}

\section{Abstract}

School, despite its often-violent facts, is an agent for socialization and change. This paper recommends policies for overcoming or reducing violence. It is founded on a selection of recent articles, emphasizing actions which work in learning how to live together. Some logic actions detected are school actors inculpating each other for school failure, silencing constructive criticism, as well as minimizing articulation between information and formative actions. Overcoming these logics would lead to violence reduction. This opens alternatives for curricula builders and developers, administrators, teacher educators and educators in general. This article concludes that corporal punishments, humiliations, stigmatization, and intolerance reach negative results; however, listening to victims, building stronger relations between parents and school, changing punishment and avoiding inculpating games between students and teachers produce positive outcomes.

Keywords: Peaceful social interaction. School violence. Action logics. Education. Dialogue.

\section{Aprender a vivir, sin violencia: ¿qué funciona y qué no funciona?}

\section{Resumen}

Considerada aún como agente de socialización y cambio, la escuela es palco de la violencia. En este trabajo se presentan recomendaciones para superación o reducción del problema, y se fundamenta en investigación de la literatura, con énfasis en las acciones escolares con buenos resultados en el aprendizaje para concretizar una adecuada convivencia social. Algunas lógicas de acción presentadas son: actores escolares se culpan recíprocamente por el fracaso escolar, yguardan silencio sobre la crítica constructiva y no hacen la debida articulación entre informar y formar. Se concluye que la superación de estas lógicas puede contribuir para la resolución de la violencia. Así, emergen posibilidades para elaboradores y ejecutores de currículos, educadores, administradores, formadores de maestros y profesores. Se concluye que los castigos corporales, humillaciones, estigmatización e intolerancia tienen efectos negativos. Lo contrario ocurre con la escuch a las victimas, la aproximación entre los padres y la escuela, el cambio de las puniciones y el fin de los juegos de culpabilización entre estudiantes y maestros y entre estos, los padres y la comunidad.

Palabras clave: Convivencia. Violencia escolar. Lógicas de acción. Pedagogía. Diálogo. 


\section{Referências}

ARREGUY, M. E.; COUTINHO, L. G. Considerações sobre afetos e violências no espaço escolar: conversações com professores. Educação em Revista, v. 31, n. 3, p. 279-98, 2015. https://doi.org/10.1590/0102-4698132854

BEEBY, C. E. Educação e desenvolvimento econômico. 3. ed. Rio de Janeiro: Zahar, 1979.

BISPO, F. S.; LIMA, N. L. A violência no contexto escolar: uma leitura interdisciplinar. Educação em Revista, v. 30, n. 2, p. 161-80, 2014. https://doi.org/10.1590/S0102-46982014000200008

BOURDIEU, P.; PASSERON, J.-C. Les héritiers: les étudiants et la culture. Paris: Éd. de Minuit, 1964.

BRASIL. E-Mec. Brasília: Ministério da Educação, 2016. Disponível em: http://emec.mec.gov.br/. Acesso em: 7 nov. 2016.

BRUNSSON, N. The consequences of decision-making. Oxford: Oxford University Press, 2007.

CAEIRO, J.; DELGADO, P. Indisciplina em contexto escolar. Lisboa: Instituto Piaget, 2005.

CARRASCO-AGUILAR, C. L. et al. Concepciones de infancia en una escuela con altos índices de violencia escolar de estudiantes a profesores. Revista Latinoamericana de Ciencias Sociales, Niñez y Juventud, v. 14, n. 2, p. 1145-59, 2016. httpa://doi.org/10.11600/1692715x.14218210814

CHRISPINO, A.; GONÇALVES, D. E. Políticas públicas sistêmicas para a redução da violência: a visão de futuro e a resiliência. Ensaio: Avaliação e Políticas Públicas em Educação, v. 21, n. 81, p. 821-38, 2013. https://doi.org/10.1590/S0104-40362013000400009

COORDENAÇÃO DE APERFEIÇOAMENTO DE PESSOAL DE NÍVEL SUPERIOR - CAPES. Qualis 2014. Brasília: CAPES, 2016a. Disponível em: https://sucupira.CAPES.gov.br/sucupira/public/consultas/ coleta/veiculoPublicacaoQualis/listaConsultaGeralPeriodicos.jsf. Acesso em: 7 nov. 2016. 
. Portal de Periódicos CAPES/MEC. Brasília: CAPES, 2016b.

Disponível em: http://www.periodicos.CAPES.gov.br/. Acesso em: 7 nov. 2016.

CROCHÍK, J. L. Hierarchy, violence and bullying among students of public middle schools. Paidéia (Ribeirão Preto), v. 26, n. 65, p. 307-15, 2016. https://doi.org/10.1590/1982-43272665201608

CURY, C. R. J. Quadragésimo ano do parecer CFE no 977/65. Revista Brasileira de Educação, n. 30, p. 7-21, 2005.

CUSHMAN, K.; ROGERS, L. Fires in the middle school bathroom: advice for teachers from middle schoolers. New York, NY: The New York Press, 2009.

DAMATTA, R. O que é o Brasil? Rio de Janeiro: Rocco, 2004.

DEBARBIEUX, E. Violence à l'école: um défi mondial?

Paris: Armand Colin, 2006.

DELORS, J. et al. Educação um tesouro a descobrir: relatório para a UNESCO da comissão internacional sobre educação para o século XXI. São Paulo: Cortez, 1998.

DUBET, F. Sociologia da experiência. Lisboa: Instituto Piaget, 1994.

FRANÇA, M. T. A.; DUENHAS, R. A.; GONÇALVES, F. O. Melhoria da qualidade educacional e redução da violência através de abertura de escolas públicas nos finais de semana: uma avaliação quantitativa. Ensaio: Avaliação e Políticas Públicas em Educação, v. 21, n. 81, p. 711-38, 2013.

FREIRE, P. Pedagogia da esperança: um reencontro com a pedagogia do oprimido. 22. ed. São Paulo: Paz e Terra, 2015.

GALVÃO, A. et al. Violências escolares: implicações para a gestão e o currículo. Ensaio: Avaliação e Políticas Públicas em Educação, v. 18, n. 68, 425-42, 2010. https://doi.org/10.1590/S0104-40362010000300002

GOMES, C. A.; LIRA, A. Aprender a convivir: cómo las escuelas hacen la diferencia. Magisterio, v. 44, p. 40-4, 2010.

GOMES, C. A.; NASCIMENTO, G. A. F.; KOEHLER, S. M. F. (Orgs.). Culturas de violência, culturas de paz: da reflexão à ação de educadores, operadores do direito e defensores dos direitos humanos. Curitiba: CRV, 2012. 
GONÇALVES, A. A. O. Violência escolar no contexto da relação entre biopolítica e educação. Tese (doutorado) - Universidade Federal de Santa Catarina, Florianópolis, 2013.

\section{INSTITUTO BRASILEIRO DE INFORMAÇÃO EM CIÊNCIA E}

TECNOLOGIA - IBICT. Brasília: Ministério da Ciência, Tecnologia e Inovação, 2016. Disponível em: http://bdtd.ibict.br/vufind/. Acesso em: 7 nov. 2016.

JAEGER, W. W. Paideia: a formação do homem grego. São Paulo: Martins Fontes, 2001.

KLINGL, E. Em escolas do DF, câmeras vigiam crianças. Correio Braziliense. Brasília, 10 maio 2009. Cidades, p. 35.

LOPES, E. L. et al. A violência no contexto escolar: visão de professores de uma escola pública da cidade de Montes Claros-MG. Motricidade, v. 8, n. S2, p. 820-824, 2012.

MANZINI, R. G. P. Bullying no contexto escolar: prevenção da violência e promoção da cultura da paz na perspectiva de adultos e crianças. Tese (doutorado) - Universidade de Brasília, Brasília, DF, 2013.

MARTINS, A. M.; BOTLER, A. M. H. Conflitos, indisciplina e violência nas escolas: apresentação. Cadernos de Pesquisa, v. 46, n. 161, p. 560-4, jul./set. 2016. https://doi.org/10.1590/198053144153

MARTINS, A. M; MACHADO, C. Gestão escolar, situações de conflito e violência: campo de tensão em escolas públicas. Educar em Revista, n. 59, p. 157-73, 2016. https://doi.org/10.1590/0104-4060.44074

MENDES, C. S. Prevenção da violência escolar: avaliação de um programa de intervenção. Revista da Escola de Enfermagem da USP, v. 45, n. 3, p. 581-8, jun. 2010. https://doi.org/10.1590/S0080-62342011000300005

ORWELL, G. 1984. 29. ed. São Paulo: Companhia Editora Nacional, 2003.

PAULO, T. S.; ALMEIDA, S. F. C. Violência e escola: escuta de professores e análise das práticas profissionais de orientação psicanalítica. Brasília: Liber Livro, 2015.

PESCADOR, J. E. P.; DOMÍNGUEZ, M. R. F. Violencia escolar, un punto de vista global. Revista Interuniversitaria de Formación del Professorado, n. 41, p. 19-38, 2001. Disponível em: https://dialnet.unirioja.es/servlet/ articulo?codigo $=118100$. Acesso em: 7 nov. 2016. 
POSSATO et al. O mediador de conflitos escolares: experiências na América do Sul. Pedagogia Escolar e Educacional, São Paulo, v. 20, n. 2, p. 357-66, maio/ago. 2016. https://doi.org/10.1590/2175-353920150202992

PRIETO QUEZADA, M. T. La violencia, que nos toca a todos: una mirada desde la historia del maltrato en la escuela. Ensaio: Avaliação e Políticas Públicas em Educação, v. 20, n. 75, p. 243-60, 2012. https://doi.org/10.1590/S0104-40362012000200002

ROGGERO, R. Contradições na educação superior: o perfil do jovem contemporâneo e o discurso pedagógico. Acta Semiótica e Linguística, v. 11, n. 30, p. 167-85, 2007.

\section{ROSSER LIMIÑANA, A. M.; SURIÁ MARTÍNEZ, R.; VILLEGAS}

CASTRILLO, E. La exposición a violencia de género y su repercusión en la adaptación escolar de los menores. Revista de Pedagogía, v. 67, n. 2, p. 117-30, 2015. Disponível em: https://dialnet.unirioja.es/servlet/ articulo?codigo $=5016142$. Acesso em: 7 nov. 2016.

ROUSSEAU, J.-J. Emílio, ou, da educação. São Paulo: Edipro, 2017.

RUOTTI, C. Violência em meio escolar: fatos e representações na produção da realidade. Educação e Pesquisa, v. 36, n. 1, p. 339-55, 2010. https://doi.org/10.1590/S1517-97022010000100010

SANTOS, A. K. C.; RAMOS, N. Violência e bullying em contexto escolar: contributos da perspectiva intercultural. Cadernos de Pesquisa, v. 23, n. 2, p. 16-30, maio/ago. 2016. http://dx.doi.org/10.18764/2178-2229.v23n2p16-30

SEBASTIÃO, J. Violência na escola, processos de socialização e formas de regulação. Sociologia, Problemas e Práticas, n. 71, p. 23-37, 2013. Disponível em: https://spp.revues.org/933. Acesso em: 7 nov. 2016.

SILVA, M. A violência da escola na voz de futuros professores: uma probabilidade da produção da cultura da violência em ambientes escolares. Educar em Revista, n. 49, p. 339-53, jul./set. 2013. https://doi.org/10.1590/S0104-40602013000300019

STELKO-PEREIRA, A. C. Avaliação de um programa preventivo de violência escolar: planejamento, implantação e eficácia. Tese (doutorado) Universidade Federal de São Carlos, São Carlos, 2012. 
TEIXEIRA, A. S. Valores proclamados e valores reais nas instituições escolares brasileiras. Revista Brasileira de Estudos Pedagógicos, v. 37, n. 86, p. 59-79, 1962. Disponível em: http://www.bvanisioteixeira.ufba.br/index. html. Acesso em: 7 nov. 2016.

VASCONCELOS, I. C. O.; GOMES, C. A. C. Jovens estudantes universitários e seus professores em interação social. Atos de Pesquisa em Educação, v. 10, n. 2, p. 605-62, 2015. Disponível em: http://proxy.furb.br/ojs/index.php/ atosdepesquisa/article/view/4316. Acesso em: 7 nov. 2016.

. Pedagogia dialógica para democratizar a educação superior. Ensaio: Avaliação e Políticas Públicas em Educação, v. 24, n. 92, p. 579-608, jul./set. 2016. https://doi.org/10.1590/S0104-40362016000300004

VENTURA, A.; PEDROSA VICO, B.; VENTURA, R. Bullying e formação de professores: contributos para um diagnóstico. Ensaio: Avaliação e Políticas Públicas em Educação, v. 24, n. 93, p. 990-1012, 2016. https://doi.org/10.1590/S0104-403620160004000010

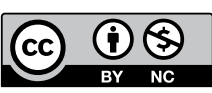

\section{Informações do autor}

Ivar César Oliveira de Vasconcelos: Doutorado em Educação pela Universidade Católica de Brasília (UCB), onde é professor do Programa e Pós-Graduação stricto sensu em Educação. Professor titular da Universidade Paulista (UNIP), no Instituto de Ciências Sociais e Comunicação. Contato: ivcov@hotmail.com 